DOI: https://doi.org/10.47405/mjssh.v6i8.982

\begin{tabular}{|c|c|}
\hline 4.581 & Malaysian Journal of Social Sciences and Humanities (MJSSH) \\
\hline $\begin{array}{l}\text { Malaysian Journal of } \\
\text { Social cciences and }\end{array}$ & Volume 6, Issue 8, August 2021 \\
\hline (MJ-SSH) & e-ISSN : 2504-8562 \\
\hline & $\begin{array}{l}\text { Journal home page: } \\
\text { www.msocialsciences.com }\end{array}$ \\
\hline
\end{tabular}

\title{
Barriers Analysis on Consumer Usage Intention of Freelance Marketplace in Indonesia
}

\author{
Palita Rana Putinagari ${ }^{1}$, Fitri Aprilianty ${ }^{1}$ \\ ${ }^{1}$ School of Business and Management, Bandung Institute of Technology, Indonesia \\ Correspondence: Palita Rana Putinagari (palita_rana@sbm-itb.ac.id)
}

\begin{abstract}
Past studies have shown that the informal sector, including freelancers, contributes significantly towards Indonesia's rate of employment by providing economic opportunities to those who cannot be absorbed by the formal sectors. Seizing this opportunity, many businesses are tapping into providing freelancers a place to sell and market their services online, commonly known as freelance marketplace. Yet the penetration of these platforms is still low in Indonesia. While the supply is high, Indonesian consumers still have doubts to use these marketplaces as their go-to platform when searching for freelancers. Thus, this study aims to investigate factors that impede consumers intention to use freelance marketplace in Indonesia, based on the framework of Innovation Resistance Theory (IRT). The data was collected from 370 respondents through online questionnaires, analyzed using Smart PLS software, and interviews, deciphered using selective coding. The results suggest that usage barrier, value barrier, tradition barrier, and image barrier negatively influence consumers' usage intention of freelance marketplace, all except for risk barrier. Additionally, social influence also has a significant effect on value barrier and image barrier. These findings can be useful to construct business strategies for online freelance service providers, by focusing to eliminate the critical barriers mentioned in this study.
\end{abstract}

Keywords: freelance marketplace, freelancer, barrier, usage intention, social influence

\section{Introduction}

Many studies have shown that the informal sector, including those of freelancers, contributes significantly towards Indonesia's economy, particularly in terms of employment by providing economic opportunities to those who are displaced from or who cannot be absorbed by the formal sectors. Rothenberg et al. (2016) found that the informal sector employs between $61 \%$ to $70 \%$ of the total labor force in Indonesia.

A 2019 report by Bloomberg showed that one-third of Indonesia's 127 million people work in the freelance category with working hours under 35 hours per week. However, Indonesian online gig workers have relatively low income (Sucahyo et al., 2019). Nearly 50\% of workers earn IDR 1 million or less per month, and nearly $80 \%$ earn less than the minimum wage. Only around one fifth of online freelancers earn more than IDR 5 million; above the minimum wage in any region in Indonesia. This suggests that there is still a huge problem in either the consumers' low demand or the online infrastructure that may dampen their potential to reach clients and take on profitable projects. 
To solve this issue, there has been a growing number of businesses who exist to empower and market freelancers work, such as Mahajasa, Fiverr, Sribulancer, Upwork, and others. They are a local and global marketplace that simplifies the on-demand gig economy, connecting clients with talented freelancers who can accomplish projects effectively and efficiently. They cut the traditional process of matching the customers in need of a temporary worker to complete their jobs and freelancers who offer them the services.

COVID-19 further accelerated the boom of these companies. Since the beginning of the pandemic, the platforms' Apple app store ratings have risen significantly, counting up to more than 50\% upward trend (Hirschfeld, 2020). Another indicator example is the apparent growth of Fiverr revenue from 2019 to 2020 (\$27.9 million to $\$ 52.3$ million). These platforms allow all freelancers, both amateurs and experts, a virtual place to easily market their services. It depends on the freelancers whether they want to adapt to the situation by going digital or constantly refusing the technological changes.

Despite this advancement of freelance platforms, a survey by Freelancer Map in 2018 and 2020 shows that many freelancers in Indonesia specifically are still struggling to score desired amounts of projects which may be caused by the functional and psychological barriers preventing consumers from buying them.

From May 17th to May 23rd 2021, the author has conducted in-depth interviews with 6 Indonesians who have made 2 to 3 purchases in the past 3 years but have never used a freelance marketplace to place their order. This is to understand what factors hinder them from using freelance marketplace as their go-to place when making that purchase consideration. The result the author found in this interview, supported by several studies, is that the top reasons they don't use these platforms are because first, they feel like they don't need it yet. Second, they haven't known it exists until now. Third, they are more comfortable using freelancers from friends' recommendation.

The findings of the above primary research serve as the foundation for this research's development and is expected to be further classified into key barriers to create the best strategy for current and future freelance marketplaces. Therefore, the main objective of this research is to identify the key barriers that impede consumers from using freelance marketplace to purchase gig services online, and to explore the depth of relationship that those key barriers have. In the end, based on those discoveries, the author expects to craft the most suitable strategy for freelance platform providers to overcome those barriers.

\section{Literature Review}

\section{Freelance Marketplace}

The definition of a freelance marketplace is an online platform that connects freelancers with individual customers or enterprises who need to use their services (Chalimov, 2020). This type of platform is commonly in the form of a website providing detailed information about freelancers, including work history and qualifications held. In this marketplace, there must be certainty that the customer must get the results of the work they paid for, while freelancers must get payment when completing their work (Bacon et al., 2009).

\section{Social Influence}

Social influence is when an individual lacks the ability or incentive to digest information thoroughly, he or she may establish an attitude by disseminating minor facts and clues about what they are confronted with (Petty \& Cacioppo, 1986). People's opinions of a service's or technology's usefulness may improve as a result of compelling social information (Venkatesh and Davis, 2000). According to certain studies, social influence can lower risk awareness (Kim et al., 2009). Social influence also has a strong favorable impact on the image of the service marketplace, based on a research by Chang et al. (2012). 


\section{Innovation Resistance Theory}

Ram and Sheth (1989) formalized the concept of resistance to innovation as IRT, which explains customer resistance towards product, service, and technology changes. IRT refers to several sorts of consumer resistance and encompasses a broad category of functional (value, usage, risk) as well as psychological (image and tradition) barriers. However, no prior research has looked into the field of freelance marketplaces, to the best of the author's knowledge.

\section{Usage Barrier}

Usage barrier is related to the incompatibility of the innovation with the consumer's routines or habits. Without a strong performance-to-price ratio, an invention will be resisted and a substitute will be chosen (Ram \& Sheth, 1989). Innovations that need modifications to a consumer's routine require a lengthy development period before achieving customers' acceptance.

\section{Value Barrier}

N. Rammile (2012) describes value barrier as resistance to using products or services that do not meet the user's sense of performance-to-price value in comparison to other substitutes. Moorthy et al., (2017) conducted a quantitative study on the effect of poor perceived value on mobile commerce adoption intentions in Malaysia, finding that value barriers have a negative association with adoption intentions.

\section{Risk Barrier}

Risk barrier is the uncertainty surrounding the potential negative effects of adopting a product or service (Marett et al., 2015); it also symbolizes consumers' perceptions of the risks involved with an invention (Laukkanen et al., 2007). According to a study conducted by Ling et al. (2017), there is a substantial negative correlation between the intention to use new technology and perceived risk.

\section{Tradition Barrier}

Tradition barrier is when an innovation has to shift the user's established culture and consequently comes into conflict with the user's established culture. The more intense the conflict, the stronger the resistance will be (Lian and Yen, 2013). According to a 2013 study by Lian \& Yen, among those who refuse to shop for experience items online, tradition is a significant impediment to their usage intention.

\section{Image Barrier}

Image barrier suggests that a bad impression is formed as a result of the perceived complexity of the product's use. According to Fain and Roberts (1997), the image barrier in new innovations originates from the internet's general "complicated-to-use" image. Thus, some users may find technology too difficult to use, leading to a negative perception of the technology's services.

\section{Usage Intention}

Fishbein and Ajzen (1975) definition of usage intention, is "the strength of one's intention to perform a specified behavior". They posit that user adoption of a new innovation is determined by the users' intention to use the system, which in turn is determined by the users' beliefs about the system. Moreover, a research by Talwar et al. (2020), stated that functional and psychological barriers negatively affect customers' usage intention. 


\section{Conceptual Framework}

Referring to the framework proposed by Jansukpum and Kettem (2016), combined with the variable components of online experience in Constantinides' study, (2004), the author constructs the final conceptual framework for this research that can be seen in Figure 1.

Figure 1: Conceptual Framework

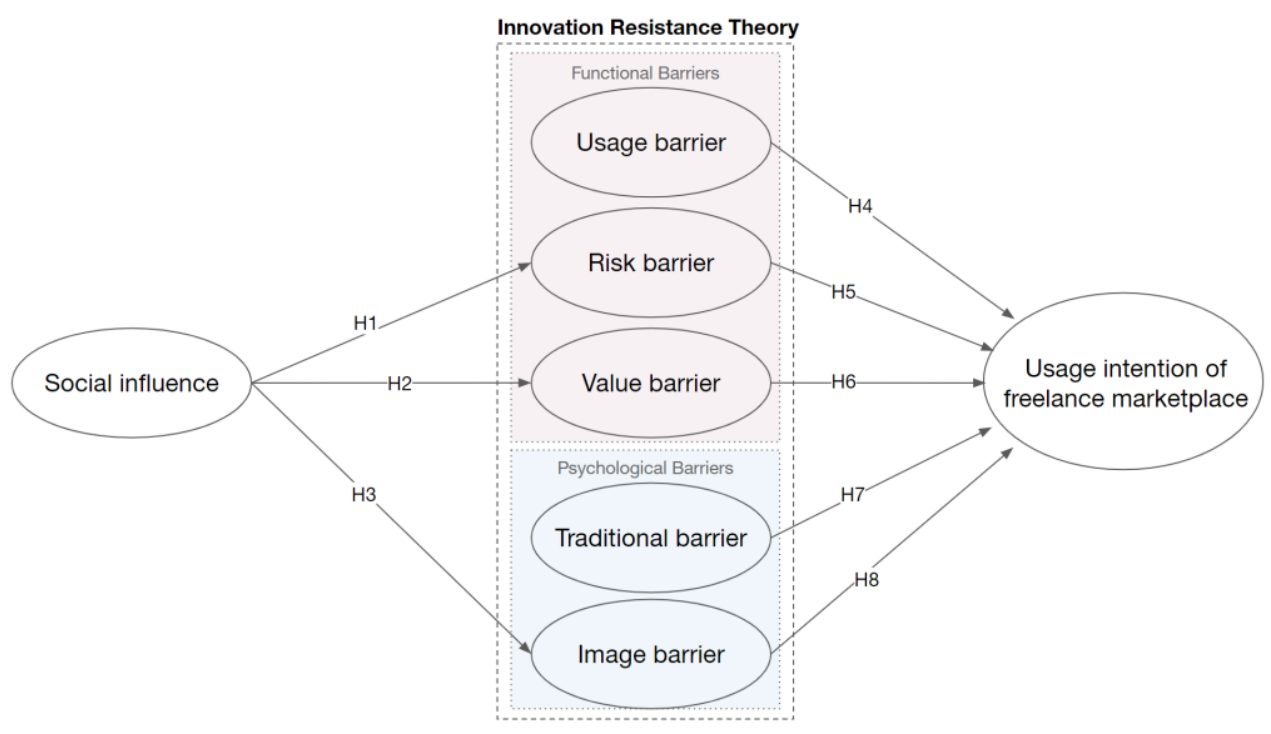

Based on the literature review and conceptual framework, the hypotheses are:

$\mathrm{H} 1$ : Social influence has a significant effect on risk barriers of using freelance marketplace.

$\mathrm{H} 2$ : Social influence has a significant effect on value barriers of using freelance marketplace.

H3: Social influence has a significant effect on image barriers of using freelance marketplace.

H4: Usage barriers have a negative effect on consumer's usage intention of freelance marketplaces.

H5: Risk barriers have a negative effect on consumer's usage intention of freelance marketplaces.

H6: Value barriers have a negative effect on consumer's usage intention of freelance marketplaces.

H7: Tradition barriers have a negative effect on consumer's usage intention of freelance marketplaces.

H8: Image barriers have a negative effect on consumer's usage intention of freelance marketplaces.

\section{Methodology}

\section{Research Design}

This study employs a quantitative method, constructing a questionnaire design to collect data from respondents and analyzing the responses using structural equation modeling. A quantitative analysis employs a set number of respondents rather than focusing on the depth of individual responses. It also shows a relationship and association between the set variables (Lucas-Alfieri, 2015). The survey results acquired via an online questionnaire will be used to examine the barriers to consumer usage intention toward freelance marketplace.

\section{Population}

The population of this study is anyone within the 18-60 age range (based on the consideration from a previous study conducted by Jungleworks, that Fiverr segment demographic is age group 15-70). They also need to have previously ordered freelance services but never on any freelance marketplace. 


\section{Sampling Procedure}

In this research, a non-probability, judgmental sampling is used. Non-probability sampling is a technique in which the respondent is chosen by the researcher based on subjective judgment (Malhotra et al., 2016). Judgmental sampling is a sampling strategy that is developed according to the research's objective or purpose. Because the goal of this study is to determine the barriers of using freelance marketplaces, the author assumes that the sample should be those who have ordered any freelance services in the past but have yet used or intrigued with the platform provided by freelance marketplaces. Malhotra et al., (2016) also stated that a problem-solving research needs a minimum sample size of 200, and this research's sample size is 338 .

\section{Data Collection}

The main research instrument to collect data in this study is a questionnaire that is divided into several sections, each with its own purposes. The first section is intended to know whether they qualify to be this research's target market. The second section is their socio-demographic information to divide them according to different segments. The third section uses open-ended questions to explore respondents' underlying reason for not using freelance marketplaces. The fourth section, which further split into several subsections, validates barriers from previous research with close-ended questions and likert scale answers, having a range from 1 (strongly disagree) to 5 (strongly agree). Then, the fifth and final section measures their usage intention.

The researcher has used a Google Form to create the questionnaire online. As for collecting as many as 338 respondents, the researcher distributed the questionnaire through Instagram, Twitter, WhatsApp and Line group chats, and paid media promotes. All questions are written in Bahasa Indonesia to make it easy for the readers to understand.

Social influence is assessed by three measurement items, referring to the studies by Venkatesh \& Davis (2000) and Kim et al. (2007). Usage barriers are assessed by four measurement items, referring to the study by Lian and Yen (2013). Risk barriers are assessed by three measurement items, referring to the studies by Laukkanen et al. (2007) and Talwar et al. (2020). Value barriers are assessed by four measurement items, referring to the studies by Laukkanen et al. (2007), Lian and Yen (2013), as well as Moorthy et al. (2016). Tradition barriers are assessed by three measurement items, referring to the studies by Moorthy et al. (2016) and Joachim et al. (2017). Image barriers are assessed by three measurement items, referring to the study by Laukkanen et al. (2007). And lastly, usage intention is measured by four measurement items, referring to the studies by Davis (1989), Liao et al. (2007), Hsu and Lu (2004), and Rahman et al. (2018).

Table 1. Distribution of Respondents' Demographic

\begin{tabular}{lll}
\hline Variable & Category & Proportion $\mathbf{( \% )}$ \\
\hline \multirow{2}{*}{ Gender } & Male & $28 \%$ \\
& Female & $72 \%$ \\
& $18-25$ & $84 \%$ \\
Age & $26-35$ & $7 \%$ \\
& $36-45$ & $5 \%$ \\
& $46-55$ & $2 \%$ \\
& $55-65$ & $2 \%$ \\
Area of Residence & Bali & $3 \%$ \\
& Jawa & $74 \%$ \\
& Kalimantan & $2 \%$ \\
& Nusa Tenggara & $1 \%$ \\
Education level & Sulawesi & $1 \%$ \\
& Sumatra & $19 \%$ \\
& Vocational school & $5 \%$ \\
& High school & $23 \%$ \\
\hline
\end{tabular}



DOI: https://doi.org/10.47405/mjssh.v6i8.982

\begin{tabular}{lll}
\hline & Bachelor & $22 \%$ \\
& Master & $5 \%$ \\
& Doctorate & $<1 \%$ \\
& Full-time student & $74 \%$ \\
& Freelancer & $1 \%$ \\
& Civil employee & $3 \%$ \\
Occupation & Private employee & $14 \%$ \\
& Entrepreneur & $5 \%$ \\
& Unemployed & $3 \%$ \\
& Retired & $<1 \%$ \\
Willingness to spend on & Rp 100,000 & $20 \%$ \\
freelance services & Rp 100,000 - Rp 500,000 & $52 \%$ \\
& Rp 500,001 - Rp 1,000,000 & $15 \%$ \\
& Rp 1,000,001 - Rp 3,000,000 & $9 \%$ \\
Freelance marketplace usage & Rp 3,000,001 - Rp 5,000,000 & $2 \%$ \\
& $>$ Rp 5,000,000 & $2 \%$ \\
& Never & $88 \%$ \\
& Have used only once/twice & $12 \%$ \\
\hline
\end{tabular}

\section{Data Analysis}

This section elaborates the measures involved in data analysis. The findings of the quantitative methodologies will be explained by the author, and the results of the analysis will be used to answer the research questions and objective.

\section{Results}

\section{Construct Validity Test}

According to Malhotra (2007), the validity test is performed to assess whether the responses are appropriate for the study. The assessment is done by calculating and analyzing the convergent and discriminant validity.

\section{Convergent Validity}

Convergent validity is the degree to which items measuring one construct converge over other constructs. The average variance extracted (AVE) criterion established by Fornell and Larcker (1981) is widely used. An AVE of at least 0.5 indicates that a latent variable can explain more than half of the variance in its indicators, indicating sufficient convergent validity (Urbach \& Ahlemann, 2010).

Table 2. AVE for Validity

\begin{tabular}{llc}
\hline Variables & Average Variance Extracted (AVE) & Validity \\
\hline Social Influence & 0.812 & Valid \\
Usage Barrier & 0.629 & Valid \\
Risk Barrier & 0.696 & Valid \\
Value Barrier & 0.631 & Valid \\
Tradition Barrier & 0.628 & Valid \\
Image Barrier & 0.693 & Valid
\end{tabular}




\section{Discriminant Validity}

Another method to check the validity is by the discriminant method, i.e. the degree to which the measures of different constructs differ from one another. It tests whether the items do not unintentionally measure something else (Urbach \& Ahlemann, 2010). Fornell and Larcker (1981) suggest that the square root of AVE of each latent variable should be greater than the correlations among the latent variables. The square root is written in bold, diagonal line in the table below.

Table 3. Discriminant Validity

\begin{tabular}{llllllll}
\hline & IB & RB & SI & TB & UB & UI & VB \\
\hline IB & 0.833 & & & & & \\
RB & 0.297 & 0.834 & & & & & \\
SI & 0.132 & 0.233 & 0.901 & & & & \\
TB & 0.311 & 0.218 & 0.137 & 0.793 & & & \\
UB & 0.575 & 0.288 & 0.253 & 0.371 & 0.793 & & \\
UI & 0.496 & 0.229 & 0.218 & 0.339 & 0.507 & 0.826 & \\
VB & 0.390 & 0.418 & 0.265 & 0.309 & 0.431 & 0.402 & 0.794 \\
\hline
\end{tabular}

\section{Indicator Reliability Test}

Indicator reliability describes the extent to which a variable or set of variables is consistent regarding what it intends to measure. The reliability of one construct is independent of and calculated separately from that of other constructs (Urbach \& Ahlemann, 2010). A score of 0.70 or higher is preferred (Wong, 2013). The calculation in the table below shows that every indicator is reliable, after it has gone several eliminations in the original one.

Table 4. Factor Loadings

\begin{tabular}{llll}
\hline Variables & Indicator & Outer Loadings & Reliability \\
Social Influence & SI1 & 0.872 & Reliable \\
& SI2 & 0.930 & Reliable \\
& SI3 & 0.900 & Reliable \\
Usage Barrier & UB1 & 0.744 & Reliable \\
& UB2 & 0.798 & Reliable \\
& UB3 & 0.894 & Reliable \\
Risk Barrier & UB4 & 0.824 & Reliable \\
\hline
\end{tabular}



DOI: https://doi.org/10.47405/mjssh.v6i8.982

\begin{tabular}{llll}
\hline Variables & Indicator & Outer Loadings & Reliability \\
RB2 & 0.850 & Reliable \\
RB3 & 0.784 & Reliable \\
Value Barrier & VB1 & 0.796 & Reliable \\
& VB2 & 0.810 & Reliable \\
& VB3 & 0.820 & Reliable \\
Tradition Barrier & VB4 & 0.749 & Reliable \\
TB1 & 0.748 & Reliable \\
Image Barrier & TB2 & 0.906 & Reliable \\
& TB3 & 0.711 & Reliable \\
& IB1 & 0.774 & Reliable \\
& IB2 & 0.866 & Reliable \\
& IB3 & 0.855 & Reliable \\
Usage Intention & UI1 & 0.836 & Reliable \\
& U12 & 0.841 & Reliable \\
& UI3 & 0.860 & Reliable \\
& UI4 & 0.765 & Reliable \\
\hline
\end{tabular}

\section{Internal Consistency Reliability}

Internal consistency in reliability suggests that the items on a measure should correlate highly with each other if they truly represent appropriate sampling (Henson, 2001). If indicators in one variable are highly correlated, it is theoretically assumed that the construct of interest has been measured to some degree of consistency. Wong (2013) stated that internal consistency is measured by composite reliability which should be 0.7 or higher.

Table 5. Internal Consistency Reliability

\begin{tabular}{ll}
\hline Variables & Composite Reliability \\
\hline Social Influence & 0.928 \\
Usage Barrier & 0.871 \\
Risk Barrier & 0.873 \\
Value Barrier & 0.872 \\
Tradition Barrier & 0.834 \\
Image Barrier & 0.871 \\
Usage Intention & 0.896 \\
\hline
\end{tabular}




\section{Hypotheses Testing}

Table 6 shows the hypothesis test analysis result from this research. There are eight hypotheses being tested on this research. The first three are regarding the effect of social influence on risk, value, and image barriers. While the other five hypothesize that image, risk, tradition, usage, and value barriers have a negative influence towards usage intention. Based on the results, all the hypotheses except for risk barrier towards usage intention are valid because the p-value is more than 1.96 and the $t$ - statistics is less than 0.5. In addition to that, the original sample shows a positive result from image, tradition, usage, and value barriers towards usage intention variable that has been inverted. Therefore, we can conclude that social influence (SI) has a significant effect on risk, value, and image barriers. Moreover, value barriers (VB), usage barriers (UB), tradition barriers (TB), and image barriers (IB) all negatively influence consumers' usage intention (UI) of freelance marketplace.

Table 6. Hypotheses Result

\begin{tabular}{llllll}
\hline $\begin{array}{l}\text { Hypo- } \\
\text { thesis }\end{array}$ & Structural Path & $\begin{array}{l}\text { Original } \\
\text { Sample }(\mathbf{O})\end{array}$ & $\begin{array}{l}\text { T Stats } \\
(\mid \mathbf{O} / \text { STEV })\end{array}$ & $\begin{array}{l}\text { P } \\
\text { Value }\end{array}$ & Decision \\
\hline H1 & Social Influence* $\rightarrow$ Risk Barrier & 0.218 & 3.985 & $\mathbf{0 . 0 0 0}$ & Accepted \\
H2 & Social Influence* $\rightarrow$ Value Barrier & 0.265 & 4.469 & $\mathbf{0 . 0 0 0}$ & Accepted \\
H3 & Social Influence* $\rightarrow$ Image Barrier & 0.132 & 2.100 & $\mathbf{0 . 0 3 6}$ & Accepted \\
H4 & Usage Barrier $\rightarrow$ Usage Intention* & 0.250 & 4.342 & $\mathbf{0 . 0 0 0}$ & Accepted \\
H5 & Risk Barrier $\rightarrow$ Usage Intention* & -0.013 & 0.268 & $\mathbf{0 . 7 8 9}$ & Rejected \\
H6 & Value Barrier $\rightarrow$ Usage Intention* & 0.163 & 2.547 & $\mathbf{0 . 0 1 1}$ & Accepted \\
H7 & Tradition Barrier $\rightarrow$ Usage Intention* & 0.119 & 2.494 & $\mathbf{0 . 0 1 3}$ & Accepted \\
H8 & Image Barrier $\rightarrow$ Usage Intention* & 0.256 & 3.654 & $\mathbf{0 . 0 0 0}$ & Accepted \\
\hline
\end{tabular}

$*=$ inverted variables.

\section{Discussion}

H1, H2, H3: Social influence significantly affects risk barrier, value barrier, and image barrier

People's perceptions of a service's or technology's usefulness may improve correspondingly from the social influence they receive from peers or close circles (Venkatesh and Davis, 2000). The research by Jansukpum and Kettem (2016) found that positive social influence has significant negative effect on risk barrier $(\mathrm{H} 1)$, value barrier $(\mathrm{H} 2)$, and image barrier $(\mathrm{H} 3)$. The finding in this research supports all of those hypotheses.

Case examples for the context in this research are when social peers or relatives start utilizing and recommending freelance marketplaces, their peers will feel confident in using it as well because they notice no problems or complaints from their peers (further reducing risk barriers). Many firms (e.g. freelance marketplace providers) have adopted KOL collaboration as a marketing tactic because of their powerful image and beliefs (further reducing image barriers). Finally, social influence can lower or increase value barriers based on how their peers perceive the freelance marketplace's performanceto-price (value) ratio. 
H4, H6, H7, H8: Usage barrier, value barrier, tradition barrier, and image barrier negatively affect consumers' usage intention.

In the groups of non-adopters, Lee (2013) discovered that perceived usefulness and perceived ease of use are the most important elements influencing consumers' usage intention and resistance. Szmigin and Foxall (1998) implied that consumers' willingness to use mobile phones also is linked to both functional (usage, value, risk) and psychological (tradition, image) barriers. Lian and Yen (2013) found that major barrier for people who refuse to shop online include value and tradition. By examining those previous studies and this research findings in tandem, we can see that these hypotheses are proven true. With significant t-values and p-values evidence in table 6 , usage barrier (H5), value barrier (H7), tradition barrier (H8), and image barrier (H9) negatively correlate with usage intention.

As usage barrier measures perceived usefulness and ease of use, this means that respondents find minimum convenience and efficiency to use freelance marketplaces. As for value barriers, respondents feel that using freelance marketplace offers no significant price-cut and benefits when compared to their current ways of searching freelancers. As for tradition barriers, respondents still prefer to engage in face-to-face interactions with the freelancers as well as finding them from friends' recommendation, as this way is already good enough for them. As for image barrier, respondents have doubts regarding purchasing on freelance marketplace because they feel new technology in freelance marketplace is often too complicated to be useful.

\section{H5: Risk barrier does not significantly affect usage intention.}

A risk barrier is anything that shows the public's perception of a new product or service's risk (Marett et al., 2015). It is one of the barriers that prevents consumers from trying new things. The risk barrier in the freelancing economy is related to personal data handling, financial sharing, and security. However, since this study's population is predominantly gen-Z, and 84 percent of respondents are between 18 and 25, it is unlikely that they face risk barriers. In a recent survey by Mobile Marketer, 32 percent of respondents said they were "not scared that businesses will exploit their personal internet data in a way that could affect them". They desire information that is tailored to them for a more personalized experience. This may explain why the risk barrier in this study is not as high as in others.

\section{Conclusion}

This research aims to analyze consumer barrier factors in their intention to use of freelance marketplace. The researcher discovered that there are four classified barriers in the context of freelance marketplace. The barriers are value barriers, usage barriers, tradition barriers, and image barrier. On top of that, several barriers are actually affected by the consumer's social influence, which are value barriers, risk barriers, and image barriers.

The researcher had proposed several recommendations based on the research results. First, to reduce usage barriers, businesses should boost the marketplace's ease-of-use and visibility. Second, to reduce value barriers, they may increase services affordability and payment options. Third, to reduce tradition barrier, they should tackle the 2 previous barriers first so that penetration of new behavior will be faster. Fourth and last, to reduce image barrier, they need to amplify positive testimony referrals and ease-of-use.

The limitation on this study is that the respondents' age ranges from 18 to 60 , but more than $80 \%$ of them are 18 to 25 years old, which may cause a major response tendency towards gen $\mathrm{Z}$ behavior only. Another limitation is that there is a minimum amount of paper references on the industry of freelance marketplace, let alone on the topic of its barriers. For subsequent studies, researches can broaden the cohort of respondents with comparative study among different sorts of age group or archetypes, to get a deeper knowledge of the using intention and the behavior of Indonesian consumers. Future 
researches can also continue to refine and expand the variables that substantially affecting consumers' resistance of freelance marketplaces.

\section{References}

Bacon, D. F., Chen, Y., Parkes, D., \& Rao, M. (2009). A Market-Based Approach to Software Evolution. Proceedings of the Conference on Object-Oriented Programming Systems, Languages, and Applications, OOPSLA, 973-980. https://doi.org/10.1145/1639950.1640066

Chang, S. E., Jang, Y. T. J., \& Chiu, C. K. R. (2012). E-tourism: Understanding users' intention to adopt Podcasting in tourism. Proceedings of the 2012 IEEE Network Operations and Management Symposium, NOMS 2012, 1360-1363. https://doi.org/10.1109/NOMS.2012.6212074

Constantinides, E. (2004). Influencing the online consumer's behavior: The Web experience. Internet Research, 14(2), 111-126. https://doi.org/10.1108/10662240410530835

Fornell, C., \& Larcker, D. F. (1981). Evaluating structural equation models with unobservable variables and measurement error. Journal of Marketing Research, XVIII(February), 39-50.

Henson, R. K. (2001). Understanding internal consistency reliability estimates: A conceptual primer on coefficient alpha. Measurement and Evaluation in Counseling and Development, 34(3), 177189. https://doi.org/10.1080/07481756.2002.12069034

Jansukpum, K., \& Kettem, S. (2016). Applying innovation resistance theory to understand consumer resistance of using online travel in Thailand. Proceedings - 14th International Symposium on Distributed Computing and Applications for Business, Engineering and Science, DCABES 2015, 139-142. https://doi.org/10.1109/DCABES.2015.42

Joachim, V., Spieth, P., \& Heidenreich, S. (2018). Active innovation resistance: An empirical study on functional and psychological barriers to innovation adoption in different contexts. Industrial Marketing Management, 71(March), 95-107. https://doi.org/10.1016/j.indmarman.2017.12.011

Kim, H. bumm, Kim, T. (Terry), \& Shin, S. W. (2009). Modeling roles of subjective norms and eTrust in customers' acceptance of airline B2C eCommerce websites. Tourism Management, 30(2), 266-277. https://doi.org/10.1016/j.tourman.2008.07.001

Laukkanen, T., Sinkkonen, S., Kivijärvi, M., \& Laukkanen, P. (2007). Innovation resistance among mature consumers. Journal of Consumer Marketing, 24(7), 419-427. https://doi.org/10.1108/07363760710834834

Lee, S. (2013). An integrated adoption model for e-books in a mobile environment: Evidence from South Korea. Telematics and Informatics, 30(2), 165-176. https://doi.org/10.1016/j.tele.2012.01.006

Lian, J. W., \& Yen, D. C. (2013). To buy or not to buy experience goods online: Perspective of innovation adoption barriers. Computers in Human Behavior, 29(3), 665-672. https://doi.org/10.1016/j.chb.2012.10.009

Malhotra, N. K., Birks, D. F., \& Nunan, D. (2016). Marketing Research: An Applied Approach. In The Marketing Book: Seventh Edition. https://doi.org/10.4324/9781315890005

Marett, K., Pearson, A. W., Pearson, R. A., \& Bergiel, E. (2015). Using mobile devices in a high risk context: The role of risk and trust in an exploratory study in Afghanistan. Technology in Society, 41, 54-64. https://doi.org/10.1016/j.techsoc.2014.11.002

Moorthy, K., Suet Ling, C., Weng Fatt, Y., Mun Yee, C., Ket Yin, E. C., Sin Yee, K., \& Kok Wei, L. (2017). Barriers of mobile commerce adoption intention: Perceptions of generation $X$ in Malaysia. Journal of Theoretical and Applied Electronic Commerce Research, 12(2), 37-53. https://doi.org/10.4067/S0718-18762017000200004

N. Rammile. (2012). Understanding resistance to cell phone banking adoption through the application of the technology acceptance model (TAM). African Journal of Business Management, 6(1), 86-97. https://doi.org/10.5897/ajbm11.635

Petty, R. E., \& Cacioppo, J. T. (1986). The elaboration likelihood model of persuasion. Advances in Experimental Social Psychology, 19(C), 123-205. https://doi.org/10.1016/S00652601(08)60214-2

Rahman, S. ur, Khan, M. A., \& Iqbal, N. (2018). Motivations and barriers to purchasing online: understanding consumer responses. South Asian Journal of Business Studies, 7(1), 111-128. 
https://doi.org/10.1108/SAJBS-11-2016-0088

Ram, S., \& Sheth, J. (1989). Consumer resistance to innovations: The marketing problem and its solutions. Journal of Consumer Marketing, 6(2), 5-14.

Rothenberg, A. D., Gaduh, A., Burger, N. E., Chazali, C., Tjandraningsih, I., Radikun, R., Sutera, C., \& Weilant, S. (2016). Rethinking Indonesia's Informal Sector. World Development, 80, 96-113. https://doi.org/10.1016/j.worlddev.2015.11.005

Szmigin, I., \& Foxall, G. (1998). Three forms of innovation resistance: The case of retail payment methods. Technovation, 18(6-7), 459-468. https://doi.org/10.1016/S0166-4972(98)00030-3

Talwar, S., Dhir, A., Kaur, P., \& Mäntymäki, M. (2020). Barriers toward purchasing from online travel agencies. International Journal of Hospitality Management, 89(June 2019), 102593. https://doi.org/10.1016/j.ijhm.2020.102593

Urbach, N., \& Ahlemann, F. (2010). Structural Equation Modeling in Information Systems Research Using Partial Least Squares. International Conference on Information Systems, ICIS 2012, I(January 2010), 420-432.

Venkatesh, V., \& Davis, F. D. (2000). A Theoretical Extension of the Technology Acceptance Model: Four Longitudinal Field Studies. Management Science, 46(2), 186-204. https://www.jstor.org/stable/pdf/2634758.pdf

Wong, K. K. K.-K. (2013). Partial Least Squares Structural Equation Modeling (PLS-SEM) Techniques Using SmartPLS. Marketing Bulletin, 24(1), 1-32. http://marketingbulletin.massey.ac.nz/v24/mb_v24_t1_wong.pdf\%5Cnhttp://www.researchgate.net/profile/Ken_ Wong10/publication/268449353_Partial_Least_Squares_Structural_Equation_Modeling_(PLSSEM)_Techniques_Using_SmartPLS/links/54773b1b0cf293e2da25e3f3.pdf 